\title{
Observation of fracture behavior of 3-D printed specimens under rolling contact fatigue in water
}

\author{
Koshiro Mizobe ${ }^{1, a}$, Masahiro Inagaki ${ }^{1}$ and Katsuyuki Kida ${ }^{1}$ \\ ${ }^{1}$ University of Toyama, Department of mechanical engineering, 3190 Gofuku, Toyama, Japan
}

\begin{abstract}
Polymer bearing was widely used in the corrosive conditions because of its high corrosion durability. The polymer bearing had been formed using molding and machining until the new 3-D printing method was developed. In this study, we performed the rolling contact fatigue tests of the 3-D printed specimens in water and observed the fracture behaviour of the specimens. We found that the surface cracks are related to both the rolling direction and the lamination directions.
\end{abstract}

\section{Introduction}

When engineers use bearings, they require various properties from the materials such as high hardness, low friction coefficient and formability. Bearing steel is popular because of its high hardness. However, it cannot be used in oil-less conditions; for example, in dry conditions which result in direct contact between the materials, in solutions which include some corrosive materials. In these special conditions we use the polymer bearings.

Some of the good properties of polymer are selflubrication ability; light weight; and high corrosion resistance. In particular, corrosion resistance is important because wet and corrosive lubricating conditions often occur in industrial situations. Therefore researchers have studied polymer bearings in wet conditions[1-3].

Two major methods of making polymer bearing's formation are the injection molding and machining. Recently, a new 3-D printing method was developed and it had become popular because we can easily make complex and seamless parts using the method. Along with the expansion of the use of 3-D printing, researchers had focused on the effect of the laminated layers joins on the mechanical properties of the 3-D printed parts [4-5].

In this study, we performed rolling contact fatigue tests on the 3-D printed specimens in water and observed these fracture behaviour of the specimens

\section{Experimental procedure}

\subsection{Specimens}

The specimens were printed by 3-D printer (Projet 3510 HD plus, 3-D systems, Inc.). Figure 1 shows the photograph of a donut-shaped specimen. The thickness was $5 \mathrm{~mm}$, the outer diameter of each bearing was $52 \mathrm{~mm}$,

\footnotetext{
a Corresponding author: kmizobe@eng.u-toyama.ac.jp
}

the inner diameter was $25 \mathrm{~mm}$, and the pitch circle diameter was $38.5 \mathrm{~mm}$. All lamination directions were X direction and the lamination pitch was $16 \mu \mathrm{m}$. The material was ABS-like polymer (VisiJet M3X, 3-D systems, Inc.).

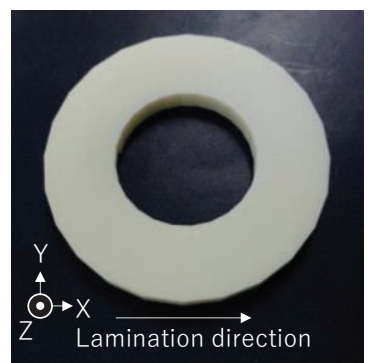

Fig. 13 -D printed specimen

\subsection{Rolling contact fatigue (RCF) test}

Before testing we cleaned all specimens in ethanol and dried by the blower. After that, we performed RCF tests using a thrust type test machine which is shown in Fig. 2. The donut-shaped specimen set under the retainer with ball. The retainer and races were designed based on the JIS B 1513 \#51305 standard. The race and retainer material were PEEK (Dupont-Mitsui). The retainer has nine $9.525 \mathrm{~mm}(3 / 8$ inch) diameter $\mathrm{Al} 2 \mathrm{O} 3$ balls. The outer, inner and pitch circle diameter were similar to the donut-shaped specimen

The tests were done in water conditions. The specimens set-up was similar to our previous work[6]. The rotation speed (rpm) was $1200 \mathrm{rpm}$ and the total number of rotations was $2.88 \times 10^{5}$ cycles. This number of rotations simulated one day's working time ( 8 hours at $600 \mathrm{rpm})$. After testing the specimens were washed in ethanol and measured the weights. We observed the 
specimens using Laser Confocal Microscope (LCM, VK9710, Keyence).

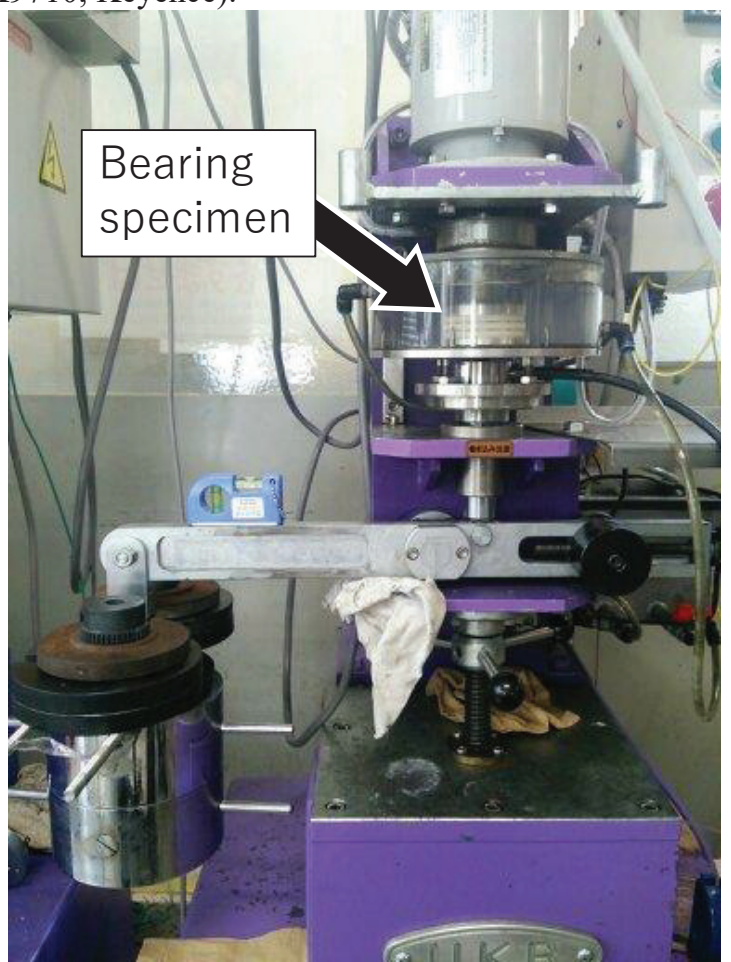

Fig. 2 RCF test set up image

\section{Results and discussion}

\subsection{Specimen failure}

Figure 3 shows the failure conditions of the specimens in water. In the case of the $500 \mathrm{~N}$ thrust load, the rotation of the bearing stopped because the donutshaped specimen started flaking. Under the $250 \mathrm{~N}$ thrust load, the specimen showed no signs of flaking. However, the weight increased by $13.7 \mathrm{mg}$ and this means that the water absorption of the specimen was higher than the wear weight loss. The wear loss was low which indicates that the fracture was strongly related to the flaking.

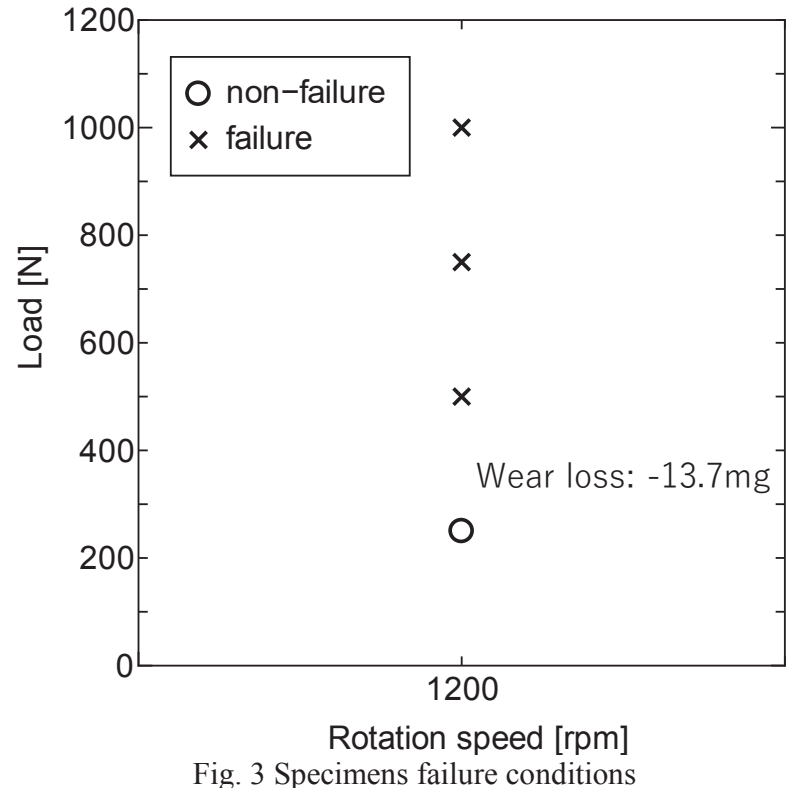

\subsection{Specimen surface observation}

We observed the specimen surfaces using a LCM. Figure 4 shows the donut-shaped specimen's surface whose lamination direction was perpendicular to the rolling direction. Figure 4(a) shows the surface before the test. We observed the lamination gaps, and the roughness of the surface was about $R_{a}=4.6 \mu \mathrm{m}$ (the measurement direction parallel to rolling direction). Figure 4(b) shows the donut-shaped specimen's surface after the $500 \mathrm{~N}$ thrust load test. The circular cracks and the deep peeling can be seen. The circular cracks are evenly distributed at increments between 50 and $100 \mu \mathrm{m}$. Figure 4(c) shows a 3-D image of Fig. 4(b). The peeling depth was over 350 $\mu \mathrm{m}$ after the $500 \mathrm{~N}$ thrust load test.

Figure 5 shows the donut-shaped specimen's surface whose lamination direction was the same as the rolling direction. Figure 5(a) shows the surface before the test. The roughness of the surface was about $R_{a}=4.0 \mu \mathrm{m}$ (the measurement direction parallel to rolling direction). Figure 5(b) shows the donut-shaped specimen's surface after the $500 \mathrm{~N}$ thrust load test. We observed a deep hole which was the result of flacking. We also observed two types of cracks, surface circular cracks which are perpendicular to the rolling direction, and cracks which are parallel to the rolling direction at the bottom of the flaking failure. Figure 5(c) shows a 3-D image of Fig. 5(b) and the two types of cracks can be clearly observed.

Figure 6 shows the donut-shaped specimen's surface whose lamination direction was 45 degrees to the rolling direction. Figure 6(a) shows the surface before the test. The roughness of the surface was about $R_{a}=4.7 \mu \mathrm{m}$ (the measurement direction parallel to rolling direction and rolling direction opposite to that in other pictures). Figure 6(b) shows the donut-shaped specimen's surface after the $500 \mathrm{~N}$ thrust load test. Some of the cracks were in the same direction as the lamination direction. Figure 6(c) shows a 3-D image of Fig. 6(b) with cracks in various directions.

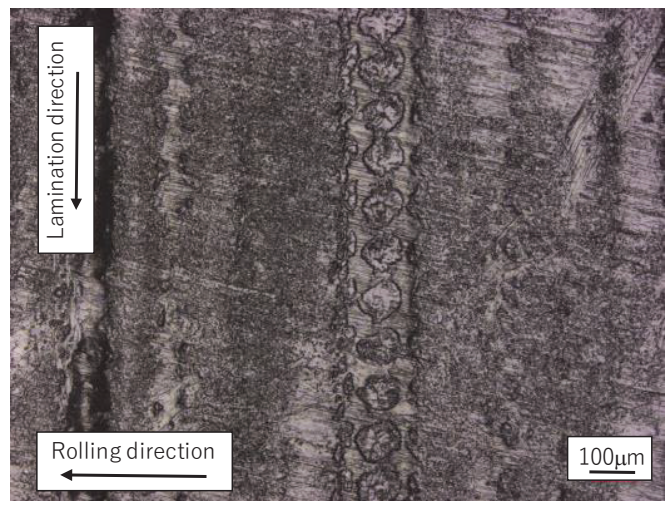

Fig. 4(a) Specimen surface before the test 


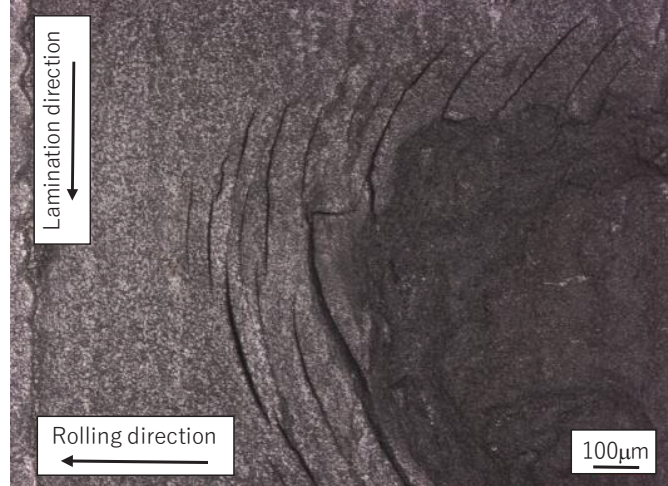

Fig. 4(b) Specimen surface after the test

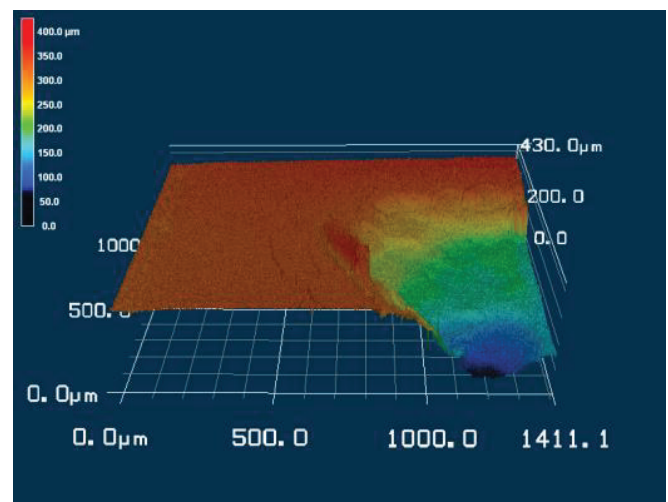

Fig. 4(c) 3-D image after the test

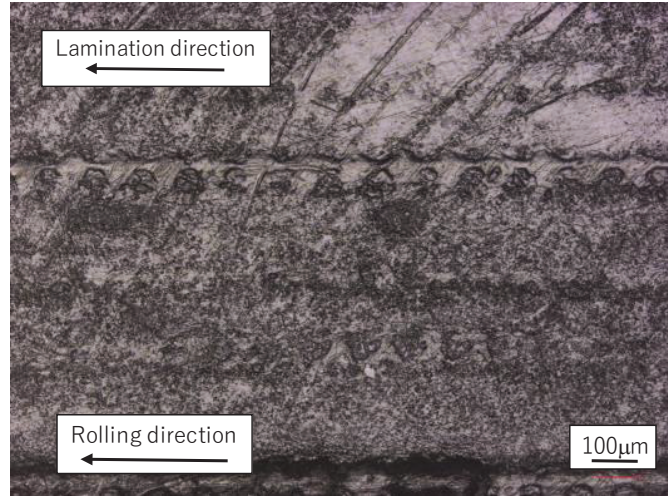

Fig. 5(a) Specimen surface before the test

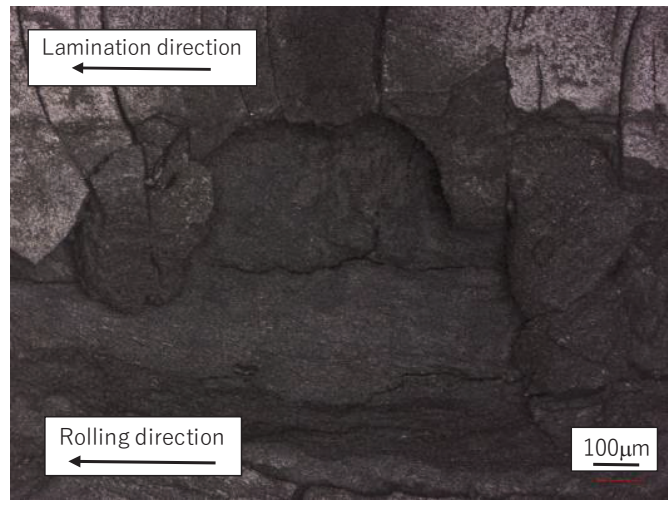

Fig.5(b) Specimen surface after the test

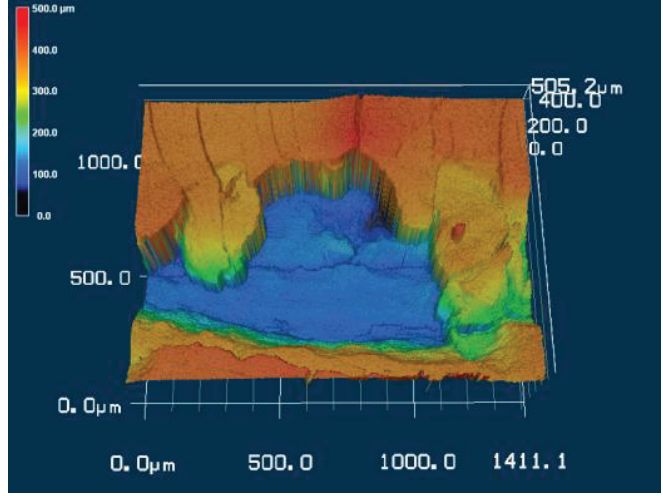

Fig. 5(c) 3-D image after the test

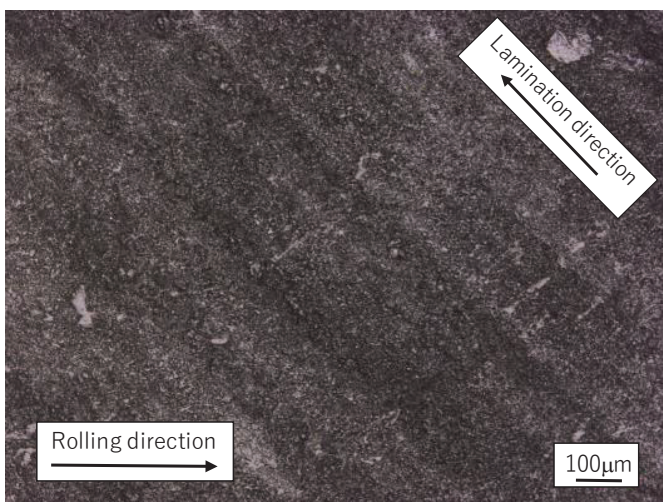

Fig. 6(a) Specimen surface before the test

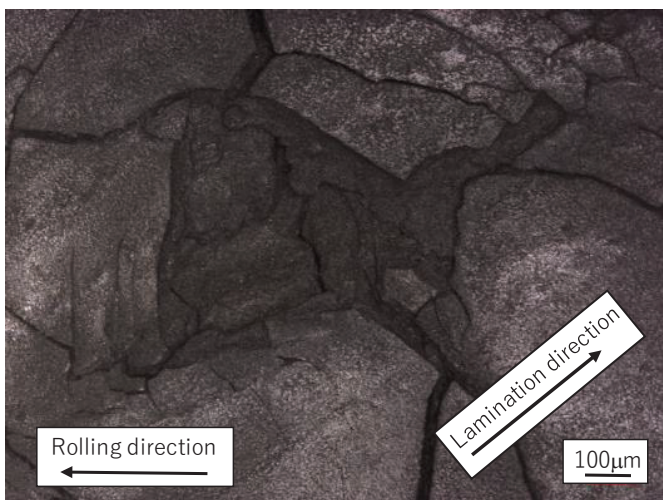

Fig. 6(b) Specimen surface after the test

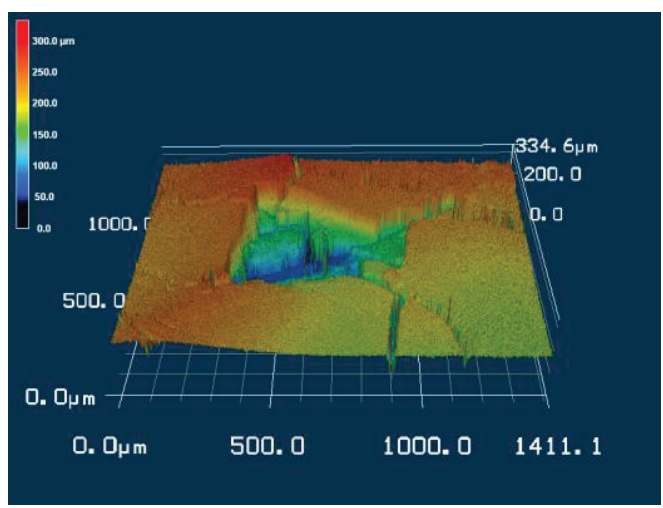

Fig. 6(c) 3-D image after the test 


\section{Conclusions}

In this study, we performed rolling contact fatigue tests on 3-D printed specimens in water and observed the fracture behaviour of the specimens. Our findings are as follows:

1. The flaking failure occurred in the 3-D printed donut-shape specimen in water.

2. When the lamination direction was parallel to the rolling direction, circular cracks perpendicular to the rolling direction were observed.

3. When the lamination direction was perpendicular to the rolling direction, two types of cracks occurred: circular cracks at the surface, and long parallel cracks at the bottom of the flaking failure.

4. When the lamination direction was 45 degrees to the rolling direction, cracks occurred in various directions.

These facts indicate that the surface cracks are related to both the rolling and lamination directions.

\section{References}

1. X. Shi, K. Kida and Y. kashima, Mat. Res. Inov. 18, 3, S42-S47 (2014)

2. R. Prehn, F. Haupert and K. Fridrich, Wear, 259 , 1-6, 693-696 (2005)

3. J. Jia, J. Chen, H. Zhou, L. Hu and L. Chen, Com. Sci. Tech. 65, 7-8, 1139-1147 (2004)

4. B. M. Tymrak, M. Kreiger and J. M. Pearce, Mat. Des. 58, 242-246 (2014)

5. J. M. G. Farstad, and O. Netland and T. Welo, Procedia CIRP, 60, 247-252 (2017)

6. X. C. Shi, M. Orito, Y. Kashima, K. Mizobe and K. Kida, Key Eng. Mat. 703, 172-177 (2016) 